ISSN 2306-1561

Automation and Control in Technical Systems (ACTS)

2014, No 1.2(9), pp. 32-43.

DOI: $10.12731 / 2306-1561-2014-1-17$

\title{
Manage customer service CRM-based technologies
}

\section{Sinha Babu Raja}

Federal Democratic Republic of Nepal, Postgraduate Student, Department of «Automated Control Systems».

State Technical University - MADI, 125319, Russian Federation, Moscow, Leningradsky prospekt, 64. Tel.: +7 (499) 151-64-12. http://www.madi.ru.

\section{dts3456@hotmail.com}

\section{Ostroukh Andrey Vladimirovich}

Russian Federation, full member RAE, Doctor of Technical Sciences, Professor, Department of «Automated Control Systems».

State Technical University - MADI, 125319, Russian Federation, Moscow, Leningradsky prospekt, 64. Tel.: +7 (499) 151-64-12. http://www.madi.ru.

\section{ostroukh@mail.ru}

Abstract. The article provides a comparative analysis of the effectiveness of methods and means of automation in solving customer service problems on the basis of CRM-technologies. Shown that the system of supply chain management (SCM) creates a common information space for all companies involved in the manufacture of the product, its transportation, sale and after-sales service.

Keywords: information systems, Customer Relationship Management (CRM), enterprise resource planning, warehouse management systems, Supply Chain Management (SCM), Total Quality Management (TQM), Enterprise Resource Planning (ERP). 
ISSN 2306-1561

Автоматизация и управление в технических системах (АУТС) 2014. - №1.2(9). - C. 32-43.

DOI: $10.12731 / 2306-1561-2014-1-17$

\section{УДК 681.3}

\section{Управление обслуживанием клиентов на основе CRM-технологий}

\section{Синха Бабу Раджа}

Федеративная Демократическая Республика Непал, аспирант кафедры «Автоматизированные системы управления».

ФГБОУ ВПО «Московский автомобильно-дорожный государственный технический университет (МАДИ)», 125319, Российская Федерация, г. Москва, Ленинградский проспект, д.64, Тел.: +7 (499) 151-64-12, http://www.madi.ru.

\section{dts3456@hotmail.com}

\section{Остроух Андрей Владимирович}

Российская Федерация, академик РАЕ, доктор технических наук, профессор кафедры «Автоматизированные системы управления».

ФГБОУ ВПО «Московский автомобильно-дорожный государственный технический университет (МАДИ)», 125319, Российская Федерация, г. Москва, Ленинградский проспект, д.64, Тел.: +7 (499) 151-64-12, http://www.madi.ru.

\section{ostroukh@mail.ru}

Аннотация. В статье проведен сравнительный анализ показателей эффективности методов и средств автоматизации, при решении проблемы обслуживания клиентов на основе CRM-технологий.

Показано, что система управления цепочками поставок (SCM) создает единое информационное пространство для всех компаний, участвующих в производстве продукта, его транспортировке, продаже и постпродажном обслуживании.

Ключевые слова: информационные системы, системы управления отношениями с клиентами (CRM), планирование ресурсов предприятия, управление складом, системы управления цепями поставок (SCM), глобальное управление гачеством (TQM), системы управления ресурсами предприятия (ERP).

\section{1. Введение}

Динамика современной деловой среды заставляет предприятия искать новые пути усиления своих конкурентных преимуществ. Для многих из них ужесточение 
конкуренции на рынках, от которых они зависят, из области внешнего воздействия все более определенно переходит в разряд важнейших внутренних проблем. В связи с этим появляется нужда в более эффективном управлении информацией, возникает необходимость внедрения CRM, особенно в оптовой торговле [1, 3, 5 - 8, 10 - 20].

Качество обслуживания клиентов - наиболее значимые факторы успеха каждого предприятия сферы услуг. Высокий уровень сервиса приводит к увеличению количества лояльных клиентов, формирует благоприятный имидж предприятия, что, в свою очередь, приводит к росту его финансовых показателей. В этой связи актуально применение CRM, т.е. направленной на построение устойчивого бизнеса концепции и бизнес-стратегии, ядром которой является "клиенто-ориентированный" подход. В этой связи возникает актуальная задача исследования систем разработки корпоративных сайтов и подходов к построению информационных систем на основе CRM для предприятий оптовой торговли.

\section{2. Традиционные маркетинговые и СRM-подходы к построению интегрированных IT-решений}

Система управления взаимоотношениями с клиентами (CRM, CRM-система, сокращение от англ. Customer Relationship Management) - прикладное программное обеспечение для организаций, предназначенное для автоматизации стратегий взаимодействия с заказчиками (клиентами), в частности, для повымения уровня продаж, оптимизащии маркетинга и улучшения обслуживания клиентов путём сохранения информации о клиентах и истории взаимоотношений с ними, установления и улучшения бизнес-процедур и последующего анализа результатов.

Инвестиции в CRM - это, безусловно, инновационный подход к развитию своего бизнеса (Таблица 1).

Таблица 1 - Сравнение традиционных маркетинговых и CRM-подходов и интегрированных IT-решений

\begin{tabular}{|c|c|c|c|c|}
\hline $\begin{array}{l}\text { Концеп- } \\
\text { ция }\end{array}$ & $\begin{array}{l}\text { Идентифика- } \\
\text { ция }\end{array}$ & $\begin{array}{l}\text { Дифференциа- } \\
\text { ция }\end{array}$ & Взаимодействие & $\begin{array}{l}\text { Персонали- } \\
\text { зация }\end{array}$ \\
\hline Задача & $\begin{array}{l}\text { Идентифика- } \\
\text { ция клиента }\end{array}$ & $\begin{array}{lr}\text { Оценка } \\
\text { и } \\
\text { потребентастей }\end{array}$ & $\begin{array}{l}\text { Создание } \\
\text { долговременных } \\
\text { взаимоот-ношений }\end{array}$ & $\begin{array}{l}\text { Реализация } \\
\text { потребностей } \\
\text { клиента }\end{array}$ \\
\hline $\begin{array}{l}\text { Традици- } \\
\text { онный } \\
\text { марке-тинг }\end{array}$ & $\begin{array}{l}\text { Неосущест- } \\
\text { вимо }\end{array}$ & $\begin{array}{l}\text { Кластерная } \\
\text { дифференциа- } \\
\text { ция }\end{array}$ & Call-центр & $\begin{array}{l}\text { Продажи } \\
\text { /услуги }\end{array}$ \\
\hline CRM & $\begin{array}{l}\text { Профилирован } \\
\text { ие личности } \\
\text { клиента }\end{array}$ & $\begin{array}{l}\text { Анализ } \\
\text { личностного } \\
\text { уровня }\end{array}$ & $\begin{array}{l}\text { Автоматизиро- } \\
\text { ванный } \\
\text { Call-центр }\end{array}$ & $\begin{array}{l}\text { Автоматиза- } \\
\text { ция продаж и } \\
\text { маркетинга }\end{array}$ \\
\hline $\begin{array}{l}\text { Техноло- } \\
\text { гические } \\
\text { решения }\end{array}$ & $\begin{array}{l}\text { Cookies и } \\
\text { персонализа- } \\
\text { ция профиля } \\
\text { Web-клиента }\end{array}$ & $\begin{array}{l}\text { Информацион- } \\
\text { ная проходка и } \\
\text { аналитика }\end{array}$ & $\begin{array}{l}\text { Интернет- } \\
\text { приложения и } \\
\text { WАР-телефония }\end{array}$ & $\begin{array}{ll}\text { ERP } & \text { и } \\
\text { электронная } & \\
\text { коммерция } & \end{array}$ \\
\hline
\end{tabular}


По данным одной из организаций, занимающихся исследованиями инноваций в бизнес - процессы, средний объём инвестиций в CRM компаний, действующих на рынках США и Европы, составил около 3 млн. дол. 69\% опрошенных утверждают, что объём их инвестиций не превысил 5 млн. USD, а более $13 \%$ вложили 10 млн. и более.

Te, кто имеет представление о внедрении ERP систем на своем предприятии, смогут оценить расходы на внедрение CRM весьма просто - следует всего лишь умножить стоимость ERP - внедрение в два раза. Сроки внедрения ERP системы в среднем составляют 2 года, причем расходы на поддержку системы в течение этих двух лет колеблются в пределах 0,4\%-1,0\% годового дохода компании.

\section{3. Результаты исследований о применении CRM}

Последние несколько ознаменовались целым рядом глобальных изменений, которые все вместе и привели к зарождению и бурному росту интереса к CRM стратегии $[1,12,20]$ :

1. Конкуренция в большинстве индустрий высока как никогда, критичным становится проблема удержания клиентов, а не приобретения новых. Согласно статистике IDC Research Group, уменьшение процента клиентов, которые уходят к конкурентам, на 5\% в год приводит к росту прибыли от $25 \%$ до $55 \%$ в зависимости от отрасли.

2. Интернет технологии привели к еще более резкому снижению барьера к смене поставщика. В реальном бизнесе конкурентов разделяют километры и часы, в виртуальном достаточно кликнуть на 5 мм в сторону и через секунду попадаешь на сайт конкурента.

3. У клиента гораздо больший выбор и легко доступна информация о рынке, так что его выбор усложнен и основан на большем количестве факторов. Компании необходимо накапливать информацию обо всех этих факторах и иметь возможность учитывать их в своих решениях.

4. У клиента гораздо больше каналов взаимодействия с подразделениями вашей компании - личная встреча, веб-сайт, электронная почта, обычная почта, телефон, факс. Клиент ожидает, что вся эта информация рассматривается вами в своей совокупности.

5. Информационные технологии позволяют с относительно низкими затратами сохранять, обрабатывать и использовать информацию о каждом случае взаимодействия с клиентом.

6. Значительное количество предприятий использует интегрированные системы (ERP и т.д.), которые автоматизируют все основные функциональные области (и потолок оптимизации за счет использования этих систем зачастую уже достигнут), в этих системах накапливается самая различная информация о клиентах, которую можно и нужно передавать между подразделениями.

7. Диапазон производимой продукции все время растет, необходимо предлагать клиентам индивидуальные решения, а для этого необходимо привлекать клиента как партнера в дизайне и производстве продукта. 
8. Если 10 - 20 лет назад речь шла о том, что необходимо значительно повышать качество продукции и все только и говорили о TQM (Total Quality Management, Глобальное Управление Качеством), то сейчас очень многие компании достигли чрезвычайно высокого уровня качества - и клиенты принимают это за данность. Конкуренция теперь идет на уровне сервиса - и не просто хорошего сервиса, а превосходного сервиса, который требует совершенно других технологий и подхода.

Ниже приведены результаты исследований о применении CRM по данным источников Gartner Research и CNews (рисунок $1-6$ ).

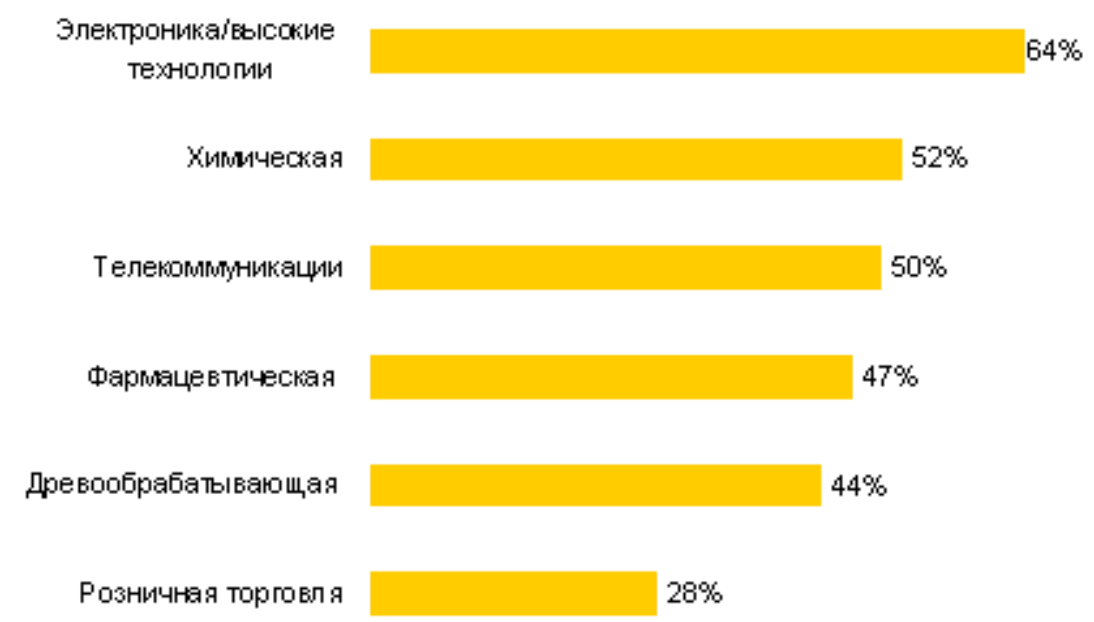

Рисунок 1 - Влияние внедрения CRM-системы на рентабельность продаж в различных отраслях

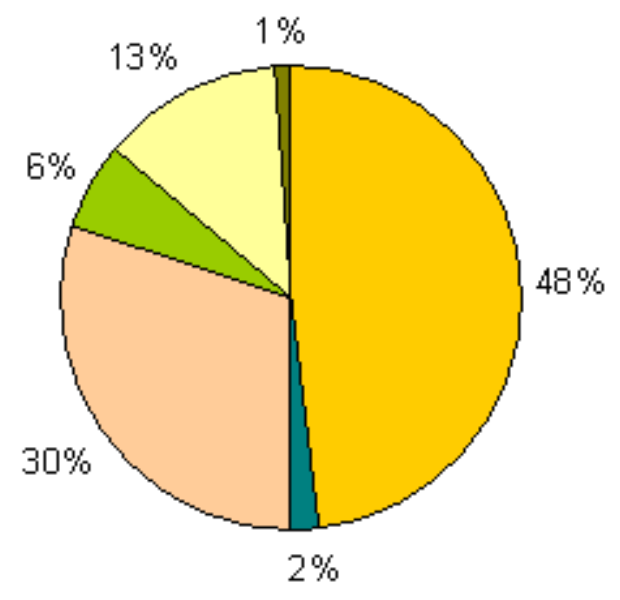

$\square$ Северная Америка

Патинская Америка

Европа

口Азия

口Япония

д ругие страны

Рисунок 2 - Региональная структура мирового рынка CRM 


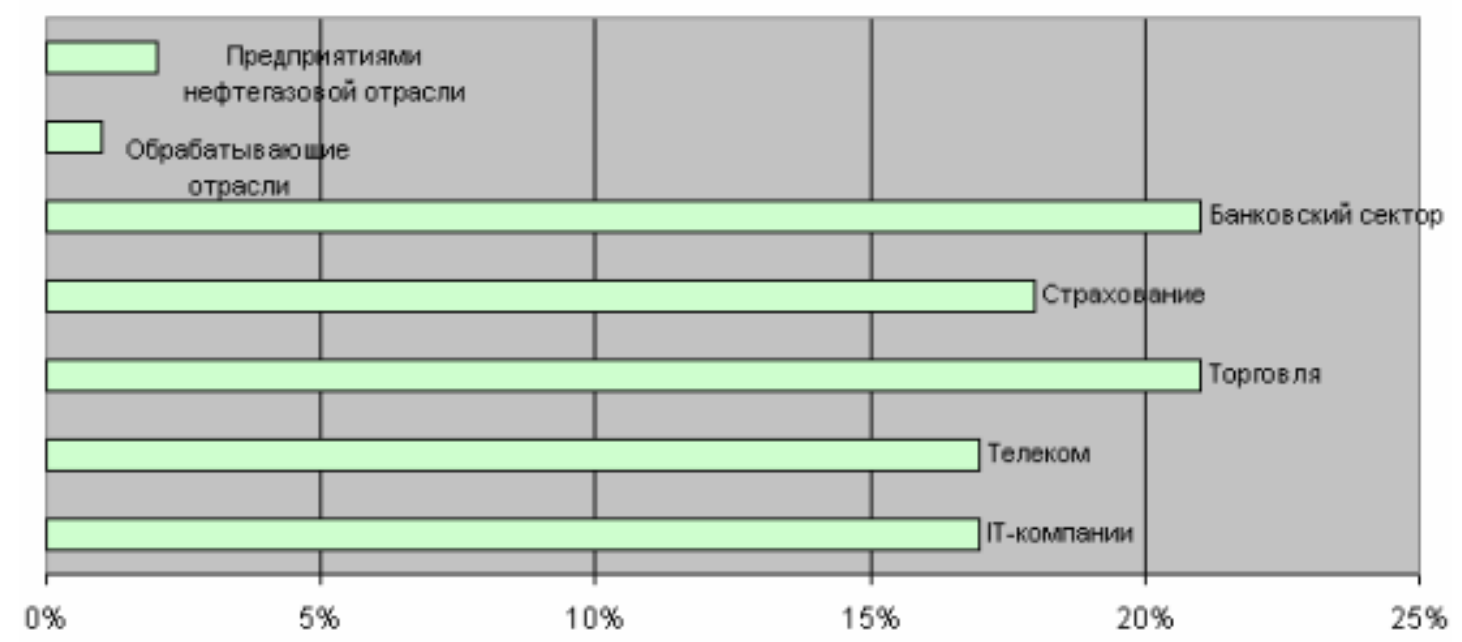

Рисунок 3 - Отрасли, в которых наиболее востребованы решения класса CRM

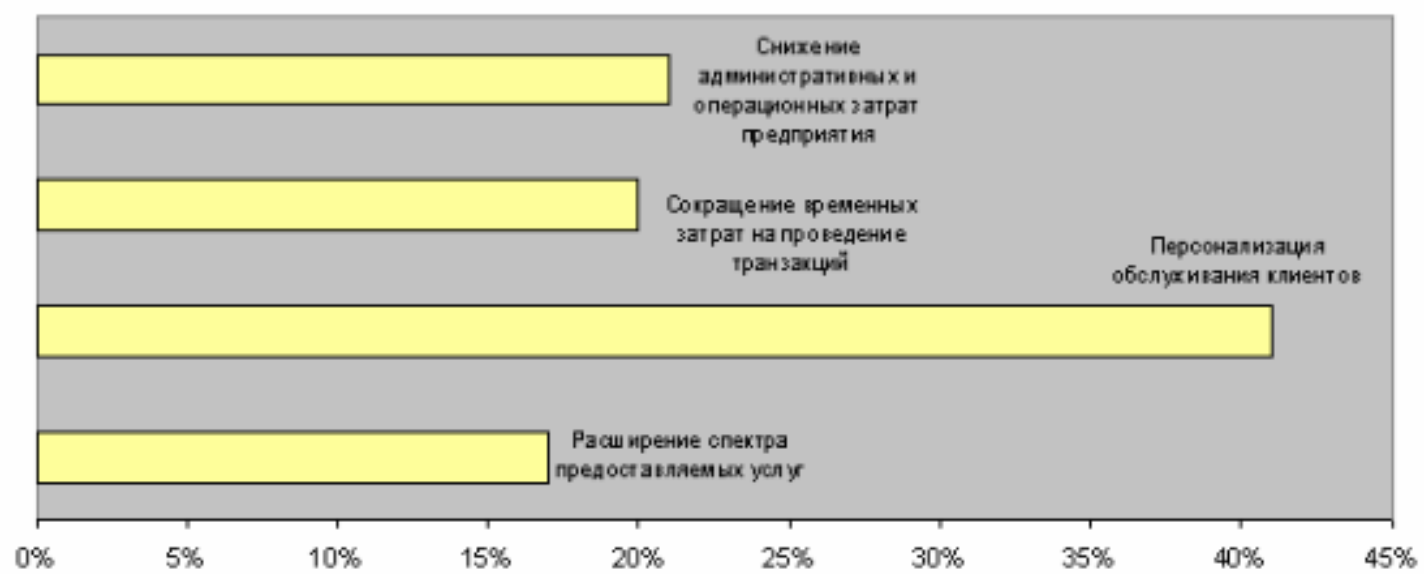

Рисунок 4 - Основные преимущества внедрения CRM-решений

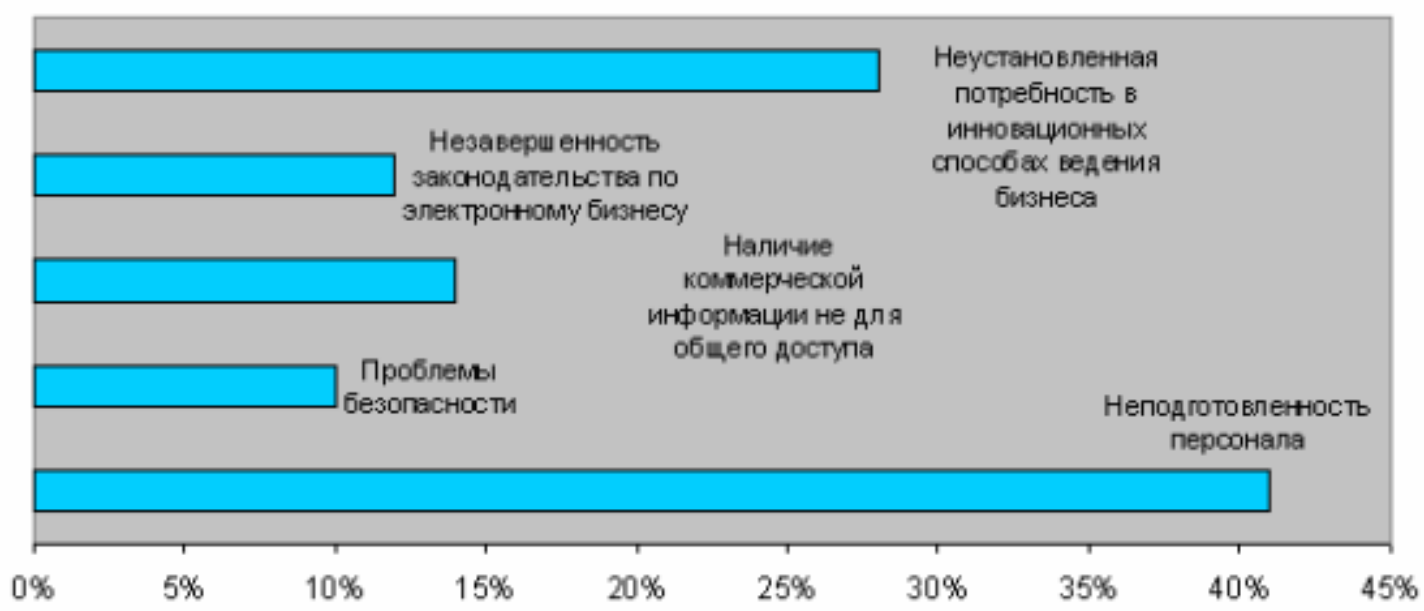

Рисунок 5 - Факторы риска при внедрении решений класса CRM 


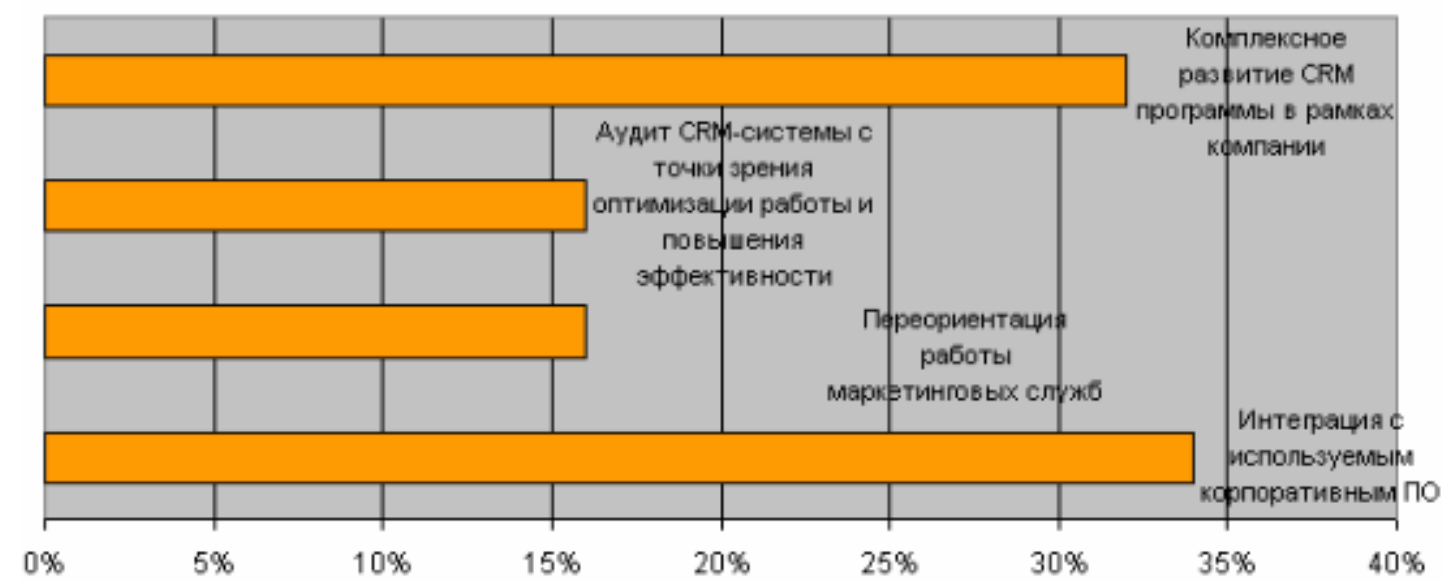

Рисунок 6 - Факторы, обеспечивающие успешное внедрение CRM в корпоративной среде

\section{4. Построение единого информационного пространства на базе CRM и SCM систем}

Для транспортных компаний, и компаний, которые используют собственный автотранспорт для перемещения грузов, актуальным является использование систем управления транспортом - TMS системы (Transport Management System). Такие системы автоматизируют процессы планирования, оптимизации и контроля грузоперевозок, организацию консолидированных перевозок, планирование и формирование маршрутов, сбор статистики и анализ данных по транспортной логистике, мониторинг перевозки, и другие [1 - 20].

Как правило, функционал перечисленных систем реализован либо в виде соответствующих модулей основной EPR системы предприятия, либо в компании используются несколько специализированных систем, тесно интегрированных между собой.

Максимальный эффект от использования систем автоматизации процессов возможен только в том случае, если эти системы работают в едином информационном пространстве [1 - 20].

Сейчас большинство компаний, внедривших у себя ERP-системы, сходятся во мнении, что автоматизированные системы планирования не решают всех задач предприятия. Для минимизации рисков, издержек, сохранения конкурентных преимуществ в условиях современной экономической и рыночной ситуации необходимо планировать и управлять не только внутренними ресурсами, но находиться в тесном взаимодействии со всеми участниками производственного процесса.

Действительно, по данным аналитической компании Gartner Group, наиболее развитыми блоками ЕRР-системы являются Финансы, Управление персоналом, Управление производством и Планирование цепей поставок (рисунок 7). 
Блоки Управления поставщиками и выполнения цепей поставок так же присутствуют, но предоставляют минимальный функционал, необходимый для поддержания целостности данных.

Такая ситуация вполне объяснима, ведь ERP системы изначально создавались для планирования ресурсов предприятия, прежде всего финансовых и производственных. Управление поставками - непрофильная для ERP системы задача. Модули управления поставщиками и выполнения перевозок присутствуют в EPR системе, как правило для обеспечения минимальной целостности данных.

\section{Оценка функциональной полноты ERP}

(по данным Gartner Group)

$\begin{array}{ll}\text { Финансы } & \mathbf{9 0 \%} \\ \text { Управление персоналом } & \mathbf{8 0 \%} \\ \text { Управление производством } & \mathbf{7 5 \%} \\ \text { Планирование цепей поставок (SCP) } & \mathbf{7 0 \%} \\ & \\ \text { Управление поставщиками (SRM) } & \mathbf{6 0 \%} \\ \text { Выполнение поставок (SCE) } & \mathbf{4 0 \%}\end{array}$

\section{Рисунок 7 - Оценка функциональной полноты ERP}

Для наглядности обратимся к рисунку 8, на котором схематично отражены потребности предприятия и какую часть этих потребностей покрывают информационные системы. Синим овалом обозначены потребности организации, большую их часть решает ERP-система, какие-то задачи решает система CRM, SCM и так далее. Все эти системы интегрированы между собой и потому на рисунке пересекаются.

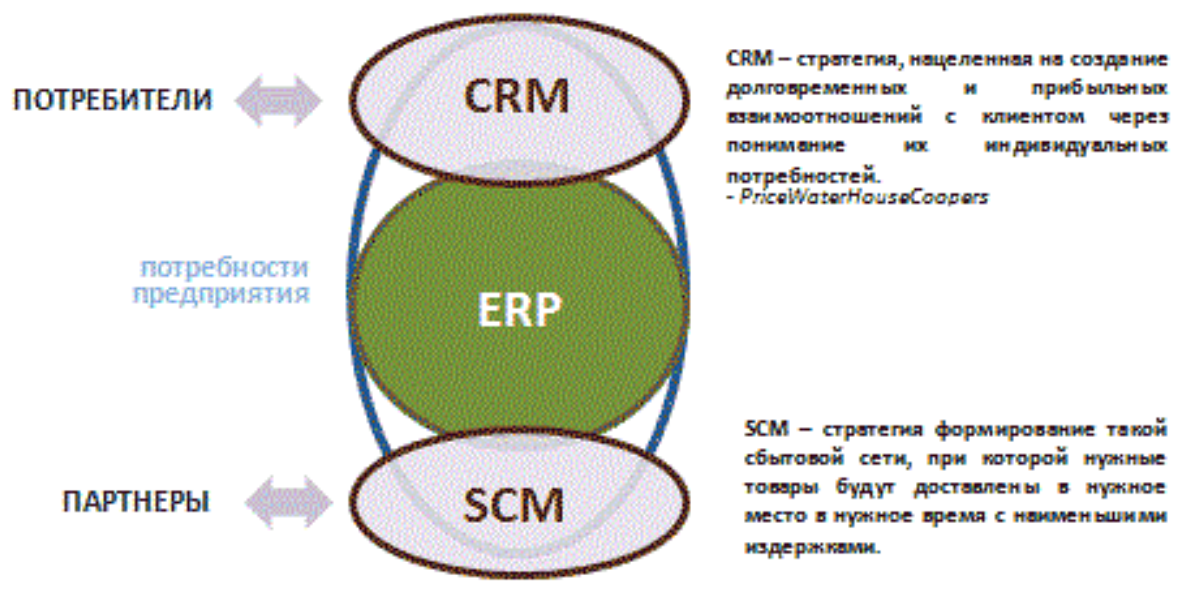

Рисунок 8 - Функционал информационных систем не охватывает все потребности предприятия 
Но и на рисунке видно, и на практике выходит так, что функционал информационных систем не охватывает все потребности предприятия.

При опредлении тех функций, которые должны быть автоматизированы, надо помнить принцип 80/20, согласно которому $20 \%$ усилий (затрат) дает $80 \%$ результата. Остальные $80 \%$ усилий - лишь $20 \%$ результата.

То есть необходимо понять тот рубеж, после которого затраты на дополнительное увеличение функционала системы не дают значимого эффекта.

При планировании корпоративной информационной системы руководство компании должно решить, какие из систем наиболее востребованы и, соответственно, должны быть наиболее развиты с функциональной точки зрения.

Международная консалтинговая компания PriceWaterhouseCoopers определяет CRM - как стратегию, нацеленную на создание долговременных и прибыльных взаимоотношений с клиентом через понимание их индивидуальных потребностей.

И, если CRM - философия работы с клиентами, SCM - философия работы с партнерами.

Концепция SCM подразумевает формирование такой сбытовой сети, при которой нужные товары будут доставлены в нужное место в нужное время с наименьшими издержками.

Достижение этой цели возможно только при эффективной интеграции поставщиков, производителей, дистрибьюторов и продавцов (рисунок 9).

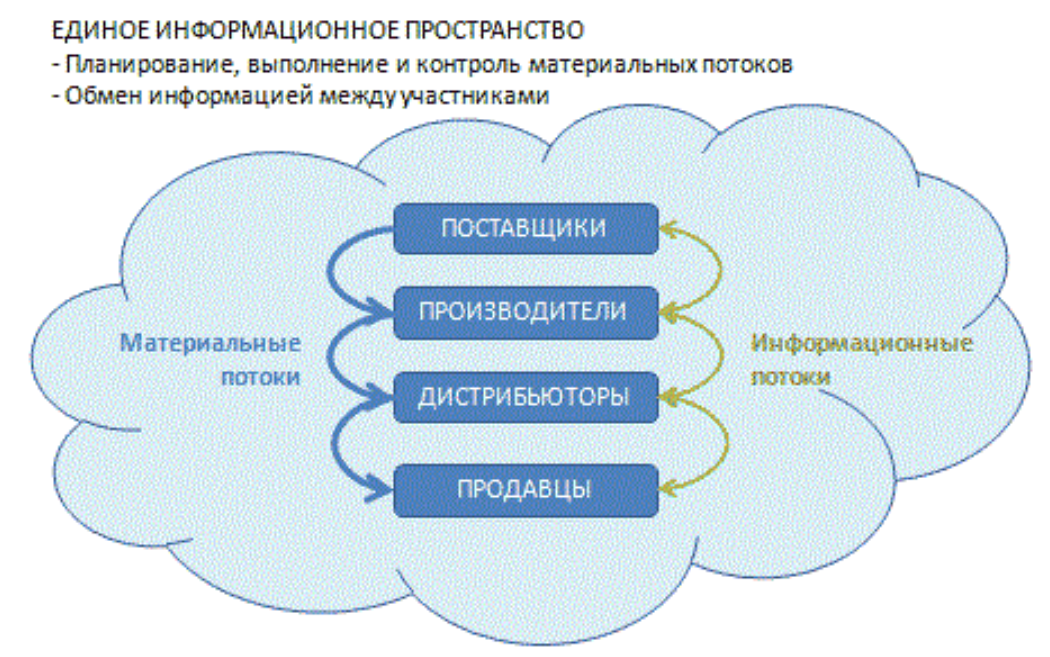

\section{Рисунок 9 - Единое информационное пространство по работе с клиентами и партнерами}

Система управления цепочками поставок представляет собой процесс организации планирования, исполнения и контроля потоков сырья, материалов, незавершенного производства, готовой продукции, а также обеспечения эффективного и быстрого сервиса за счет получения оперативной информации о перемещениях товара.

В условиях сложившейся экономической ситуации, ужесточения конкуренции и роста требований улучшения качества сервиса со стороны клиентов, чтобы сохранить 
конкурентные преимущества компаниям необходимо оптимизировать все процессы создания стоимости - от поставки сырья, до сервисного обслуживания конечного потребителя и утилизации продукции.

SCM-система обеспечивает планирование ресурсов и информационное сопровождение на протяжении всего жизненного цикла продукта - от заказа на разработку до послепродажного сервиса и утилизации, тогда как ERP система обеспечивает лишь планирование ресурсов, необходимых для разработки продукта (рисунок 10).

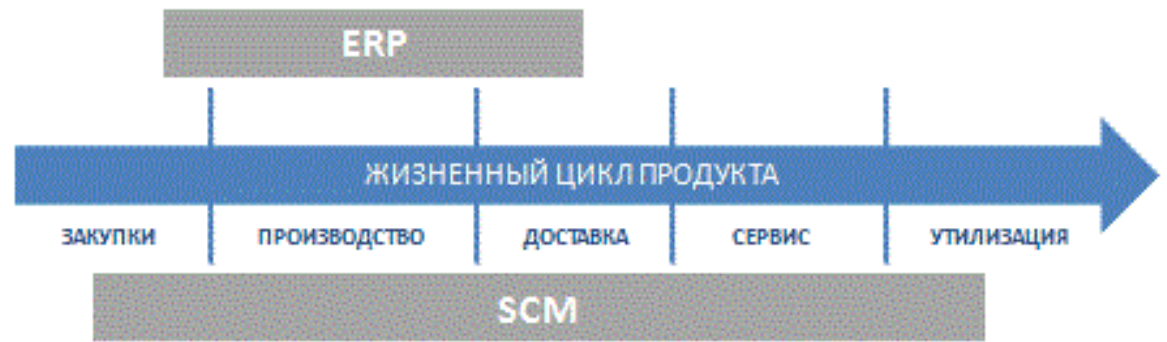

\section{Рисунок 10 - Управление жизненным циклом продукта}

ERP система обеспечивает планирование и управление ресурсами при создании предопределенных видов продуктов, допуская незначительные изменения в составе продуктов.

SCM система позволяет планировать и управлять ресурсами при создании уникальных продуктов.

По данным аналитических компаний AMR Research, Forrester Research, успешное внедрение систем управления цепочками поставок дает компаниям преимущества (рисунок 11)

\section{Преимущества от внедрения SCM}

(по данным AMR Research, Forrester Research)

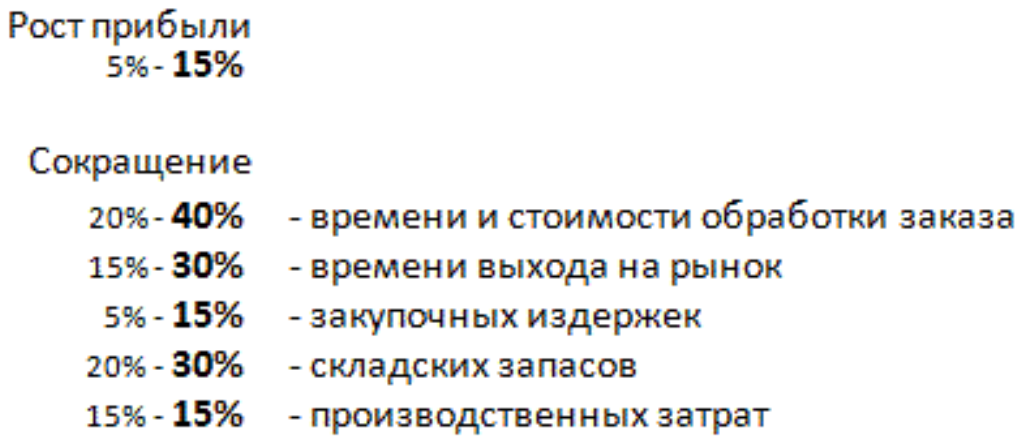

Рисунок 11 - Преимущества от внедрения SCM 
Система управления цепочками поставок создает единое информационное пространство для всех компаний, участвующих в производстве продукта, его транспортировке, продаже и постпродажном обслуживании. Благодаря этому повышается уровень обслуживания и появляются дополнительные возможности для клиента, такие как, например, отслеживание состояния заказа в режиме реального времени.

\section{5. Заключение}

Исследованы концепции создания информационных систем для управления оптовыми поставками бакалейных изделий на основе современных технологий проектирования и программной реализации.

\section{Список информационных источников}

[1] Кузнецов И.А. Особенности реализации автоматизированной информационноаналитической системы центра планирования перевозок строительных грузов / И.А. Кузнецов, А.В. Остроух // Вестник МАДИ(ГТУ). - 2008. - Вып. 1(12). - С. 92 96.

[2] Исмоилов М.И. Подготовка и переподготовка персонала предприятий промышленного и транспортного комплексов с применением мобильных технологий: монография / М.И. Исмоилов, А.Б. Николаев, А.В. Остроух. - SaintLouis, MO, USA: Publishing House Science and Innovation Center, 2013. - 166 c. ISBN 978-0-615-67111-6.

[3] Куфтинова Н.Г. Процессно-ориентированный подход к автоматизации планирования и управления транспортировкой продукции предприятий промышленности / А.В. Остроух, Н.Г. Куфтинова // Вестник МАДИ - 2010. - Вып. 4(23). - С. 62-66.

[4] Куфтинова Н.Г. Разработка информационно- логической модели транспортной сети мегаполиса / А.В. Остроух, Н.Г. Куфтинова // Бюллетень транспортной информации. - М.: Национальная ассоциация транспортников, 2013. - №1 (211). C. 23-26.

[5] Николаев А.Б. Информационные технологии в менеджменте и транспортной логистике: учебное пособие / А.Б. Николаев, А.В. Остроух. - Saint-Louis, MO, USA: Publishing House Science and Innovation Center, 2013. - 254 c. - ISBN 978-0615-67110-9.

[6] Остроух, А.В. Информационные технологии в научной и производственной деятельности / [ред. А.В. Остроух] - М: ООО "Техполиграфцентр", 2011. - 240 с. ISBN 978-5-94385-056-1.

[7] Остроух А.В. Автоматизация транспортировки продукции / Н.Г. Куфтинова, А.В. Ocтроух - Saarbrucken, Germany: LAP LAMBERT Academic Publishing, 2011. - 146 p. - ISBN 978-3-8454-1089-0.

[8] Остроух А.В. Системы планирования перевозок. Программно-технологические решения по разработке системы планирования заданий для заказных пассажирских перевозок / А.В. Остроух, А.Б. Львова, А.Р. Исмаилов. Saarbrucken, Germany: LAP LAMBERT Academic Publishing, 2013. - 121 p. - ISBN 978-3-659-43619-2. 
[9] Остроух А.В. Ввод и обработка цифровой информации: учебник для нач. проф. образования / А.В. Остроух. - М.: Издательский центр «Академия», 2012. - 288 с. - ISBN 978-5-7695-9457-1.

[10] Остроух А.В. Оперативный контроль транспортно-экспедиционной деятельности. Процессный подход к агрегированию системы показателей деятельности транспортно-экспедиционного предприятия / А.В. Остроух, А.М. Ивахненко, Н.А. Крупенский. - Saarbrucken, Germany: Palmarium Academic Publishing, 2013. - 221 p. - ISBN 978-3-659-98329-0.

[11] Остроух А.В., Тянь Юань Современные методы и подходы к построению систем управления производственно-технологической деятельностью промышленных предприятий // Автоматизация и управление в технических системах. - 2013. - № 1(3); URL: auts.esrae.ru/3-53 (дата обращения: 31.10.2013).

[12] Остроух A.В., Синха Бабу Раджа. Исследование информационных систем управления взаимоотношениями с поставщиками // Автоматизация и управление в технических системах. - 2013. - № 4.1. - C. 56-62. DOI: 10.12731/2306-15612013-4-10.

[13] Остроух А.В., Башмаков И.А. Минимизация производственных рисков при автотранспортном обслуживании потребителей бетонных смесей // Автоматизация и управление в технических системах. - 2013. - № 4.2. - С. 83-90. DOI: 10.12731/2306-1561-2013-4-40.

[14] Приходько В.М., Солнцев А.А., Саная А.Г. Сетевая теоретико-игровая модель рациональных закупок в задаче формирования адаптивного механизма согласованных цен в схеме снабжения дилерской сети // Автоматизация и управление в технических системах. - 2013. - № 1(3); URL: auts.esrae.ru/3-70 (дата обращения: 31.10.2013).

[15] Саная А.Г. Модели аппроксимации показателей экономической эффективности инновационных проектов развития дилерских сетей // Автоматизация и управление в технических системах. - 2013. - № 2(4); URL: auts.esrae.ru/4-76 (дата обращения: 31.10 .2013$)$.

[16] Солнцев А.А. Модели нечеткого ситуационного анализа при описании вложенных процессов многоцелевой деятельности дилерской сети // Автоматизация и управление в технических системах. - 2013. - № 1(3); URL: auts.esrae.ru/3-71 (дата обращения: 31.10.2013).

[17] Суркова Н.Е., Угарова Ю.Н. Организация работы ИТ-подразделения в холдинговых структурах // Автоматизация и управление в технических системах. - 2013. - № 1(3); URL: auts.esrae.ru/3-59 (дата обращения: 31.10.2013).

[18] Ostroukh A.V., Kuftinova N.G. Automation of Planning and Management of the Transportation of Production for Food Processing Industry Enterprises. Automatic Control and Computer Sciences. 2012. Vol. 46. No. 1. pp. $41-48$.

[19] Ostroukh A.V., Polgun M.B. New approaches to development of automated supervisory systems of industrial enterprises transport // International Journal of Advanced Studies (iJAS). 2013. Vol. 3, Issue 4, pp. 3-9. DOI: 10.12731/2227-930X-2013-4-1.

[20] Ostroukh A.V., Belousova A.I., Pavlov D.A., Yurchik P.F. Problems of organization and search the knowledge base in the CRM-systems // IOSR Journal of Engineering (IOSRJEN). 2014. Vol. 04. Issue 02. V3. pp. 18-23. DOI: 10.9790/3021-04231823. ANED: 0.4/3021-04231823. 